\title{
A Review of Dual-Task Walking Deficits in People with Parkinson's Disease: Motor and Cognitive Contributions, Mechanisms, and Clinical Implications
}

\author{
Valerie E. Kelly, Alexis J. Eusterbrock, and Anne Shumway-Cook \\ Department of Rehabilitation Medicine, University of Washington, 1959 NE Pacific Street, P.O. Box 356490, \\ Seattle, WA 98195-6490, USA \\ Correspondence should be addressed to Valerie E. Kelly, vekelly@uw.edu
}

Received 1 June 2011; Revised 29 August 2011; Accepted 4 September 2011

Academic Editor: Alice Nieuwboer

Copyright (๑) 2012 Valerie E. Kelly et al. This is an open access article distributed under the Creative Commons Attribution License, which permits unrestricted use, distribution, and reproduction in any medium, provided the original work is properly cited.

Gait impairments in Parkinson's disease (PD) are exacerbated under dual-task conditions requiring the simultaneous performance of cognitive or motor tasks. Dual-task walking deficits impact functional mobility, which often requires walking while performing concurrent tasks such as talking or carrying an object. The consequences of gait impairments in PD are significant and include increased disability, increased fall risk, and reduced quality of life. However, effective therapeutic interventions for dual-task walking deficits are limited. The goals of this narrative review are to describe dual-task walking deficits in people with PD, to discuss motor and cognitive factors that may contribute to these deficits, to review potential mechanisms underlying dual-task deficits, and to discuss the effect of therapeutic interventions on dual-task walking deficits in persons with PD.

\section{Introduction}

Gait impairments and walking limitations are common among people with Parkinson's disease (PD). While gait abnormalities are not pronounced in the early stages of PD, their prevalence and severity increase with disease progression. Within 3 years of diagnosis, over $85 \%$ of people with clinically probable PD develop gait problems [1]. The potential consequences of gait impairments in PD are significant and include increased disability $[2,3]$, increased risk for falls, and reduced quality of life. Falls are common among people with PD and can result in fear of falling, injury, and hospitalization [4-10]. The estimated prevalence of falls in PD ranges from 40 to $90 \%$ and increases with the duration of follow-up $[4,5,11-16]$. It is estimated that $45-$ $50 \%$ of falls in this population occur when walking $[5,17]$, with balance and walking deficits commonly identified as risk factors for falls $[5,10-12,14,18,19]$. Reduced quality of life is also associated with balance and gait abnormalities in $\mathrm{PD}$, including festination and freezing of gait $[2,20$ 24]. In fact, people with PD consider mobility and walking limitations to be among the worst aspects of the disease [25].
Mobility in daily life frequently requires walking while performing simultaneous cognitive or motor tasks, such as talking with a friend or carrying a cup of coffee. Gait impairments in people with PD are exacerbated under such dual-task conditions. In recent years, dual-task walking research has expanded rapidly. The association of gait impairments with adverse consequences like increased fall risk has motivated research into clinical strategies to assess and treat dual-task walking deficits in PD. Several recent review papers have been published on dual-task posture and gait deficits among older adults and in a general neurologic population [26-29], but none have focused specifically on people with PD. While people with PD demonstrate dualtask deficits in a variety of movements, including postural control tasks [30, 31], upper extremity movements [32, 33], and speech [34], the focus of this paper is dual-task walking. The goals of this review are to describe dual-task walking deficits in people with PD, to discuss motor and cognitive factors that may contribute to these deficits, to review potential mechanisms underlying dual-task interference, and to discuss the effect of therapeutic interventions on dual-task walking deficits in people with PD. 


\section{Dual-Task Walking Deficits in PD}

Single-task gait impairments in PD include reduced speed and stride length and increased double limb support time and stride-to-stride variability [35-38]. With progression of PD, gait abnormalities worsen, and festination, freezing, and dystonic or dyskinetic gait patterns can emerge [39]. Gait impairments in PD are exacerbated under dualtask conditions, with further reductions in gait speed and stride length [40-46], decreased symmetry and coordination between left and right steps $[47,48]$, and increased strideto-stride variability $[45,49,50]$. This section will review reported dual-task walking deficits in people with PD and will consider factors that influence the magnitude of these deficits.

\subsection{Individual, Task, and Environment Framework. Table 1} summarizes dual-task walking studies in people with PD, including relevant individual, task, and environmental characteristics of each study. Comparing dual-task walking deficits across studies is challenging because of variations in methodology. In Table 1, decrements in walking under dual-task conditions are expressed as a percentage of singletask performance, commonly referred to as the dual-task cost $($ DTC $=[$ dual-task - single-task $] /$ single-task $* 100)$ $[51,52]$. The DTC allows a more direct comparison of dualtask deficits across studies and provides a way to assess the relative effects of individual, task, and environmental factors. For example, a study by Plotnik and colleagues measured gait speed DTCs of $17 \%$ in people with moderate $\mathrm{PD}$, on medication, when walking approximately $80 \mathrm{~m}$ and performing serial-3 subtractions [45]. Lord and colleagues measured gait speed DTCs of $32 \%$ in people with moderate $\mathrm{PD}$, off medication, when walking approximately $6.5 \mathrm{~m}$ in their home while carrying a tray and counting auditory tones [43]. Dual-task walking deficits can be compared using the DTC even though these studies varied in terms of the participants' medication status, the concurrent tasks used, and the environment where walking occurred. Because multiple factors differed between studies, it is not clear whether the greater DTCs reported by Lord and colleagues are due to off-medication status, more challenging concurrent tasks, or a more complex home environment. When assessing dual-task deficits in PD, it is important to consider individual characteristics such as the severity of motor and cognitive impairments, the complexity of both walking and concurrent tasks, and the overall challenge presented by the environment.

2.2. Individual Factors. Studies of dual-task walking in PD vary substantially with respect to participant characteristics. Dual-task walking deficits increase with age among healthy adults $[29,60,61]$, but people with PD consistently demonstrate greater dual-task walking deficits than healthy, age-matched individuals $[42,44,50,54,59]$. For example, O'Shea and colleagues found that people with PD had greater dual-task declines in gait speed than healthy older adults, with gait speed DTCs of $-18 \%$ to $-19 \%$ in the PD group compared to $-7 \%$ in the control group [44]. Most research has examined people with mild-to-moderate disease severity, as measured by the Unified Parkinson Disease Rating Scale (UPDRS) and Hoehn and Yahr scores, although disease severity is associated with dual-task walking deficits $[43,57]$. The majority of studies examined the impact of concurrent task performance during the on-medication state, though a small number of studies examined dual-task walking in people with PD in the off-medication state only $[43,59]$. Studies that examined the effects of medication demonstrated improvements in dual-task walking performance on-medication compared to off-medication $[53,57]$. Some studies specifically examined individuals with PD and freezing $[53,55,59]$, motor response fluctuations [45], or a history of falls [62]. For example, research comparing people with PD and freezing to those without freezing demonstrated increased dual-task walking deficits when walking forwards, turning, and walking backwards [53, 55, 59].

2.3. Task Factors. Dual-task studies in PD also vary in terms of walking and concurrent task characteristics. Most examined walking on a level surface at a self-selected speed, but some included more complex walking tasks. For example, some walking tasks involved sit-to-stand transfers and/or turning [43, 46, 53, 54, 57-59], and one study examined backwards walking [55]. Concurrent tasks varied in terms of type (cognitive or motor), domain, and difficulty. Concurrent cognitive tasks included mental tracking, such as attentional tasks $[43,50,59]$ or arithmetic calculations [41, $42,44,45,47-50,55,56]$, verbal fluency or conversational tasks $[42,53,54]$, and memory tasks $[46,50]$. Concurrent motor tasks were used less commonly and included carrying objects $[40,43,46,57,58]$ or manipulating objects $[42,44]$. It is not clear whether motor or cognitive tasks have a greater impact on walking in people with PD. One study found similar impacts of cognitive and motor tasks [44], while other studies showed a greater impact of cognitive tasks $[42,46]$. However, the tasks incorporated differed in terms of both type and complexity, limiting the ability to make direct comparisons. Studies that controlled task domain and varied task difficulty suggest that more complex tasks have a greater effect on walking in PD $[40,54,56]$.

Typically, no specific instructions are provided regarding which task to prioritize during dual-task conditions. In most cases, participants were either instructed to focus on both tasks or instructions were not specified. However, most studies quantified dual-task changes in walking only and did not measure concurrent task performance, making it difficult to determine if there were between-task trade-offs. DTCs provide a means to assess trade-offs between walking and concurrent task performance [63]. In studies that examined dual-task changes in both walking and the concurrent task, most showed declines in both [44, 50]. Only one study demonstrated concurrent task improvements and walking declines under dual-task conditions [42], consistent with trade-offs between tasks and prioritization of the concurrent task over walking. 


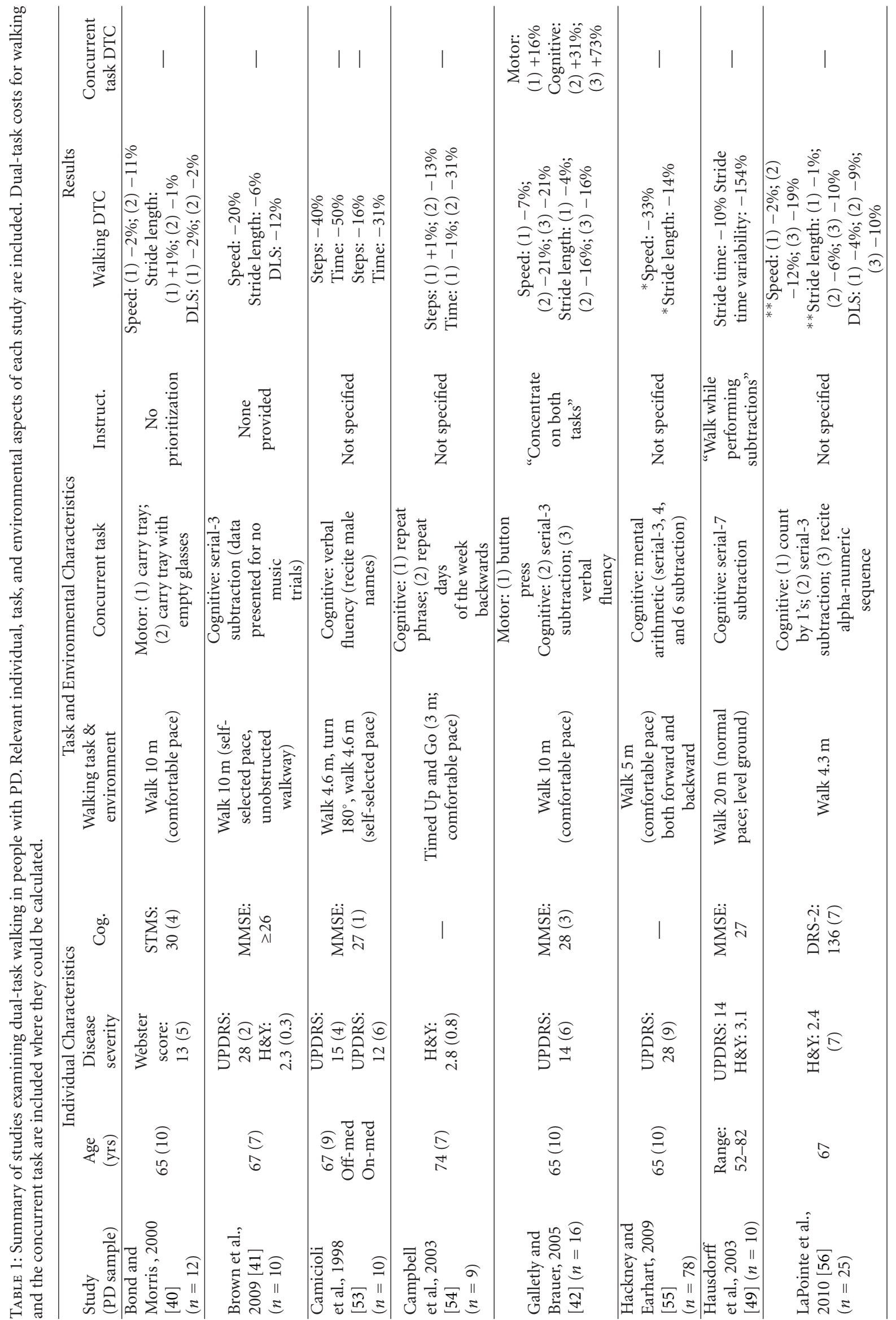




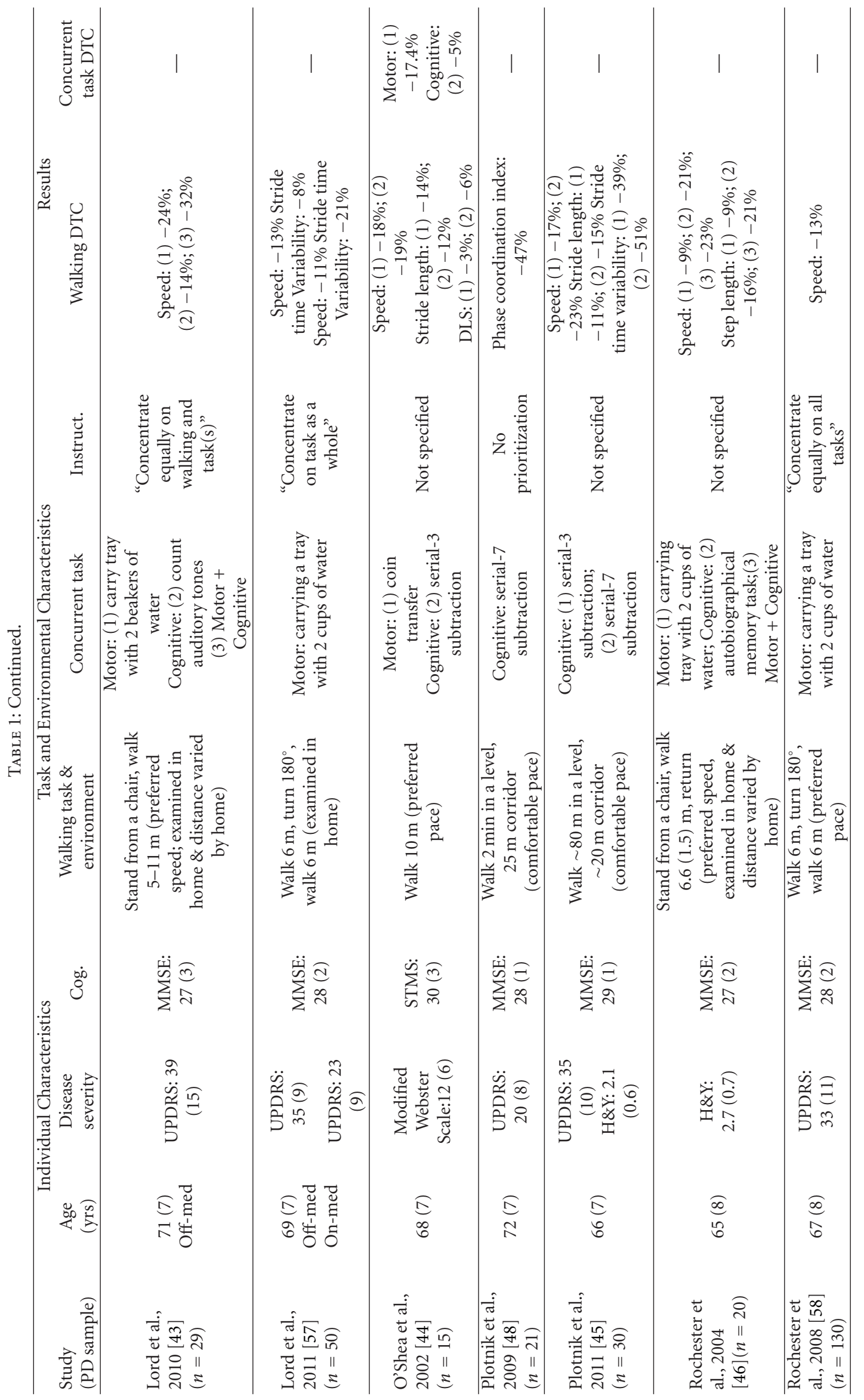




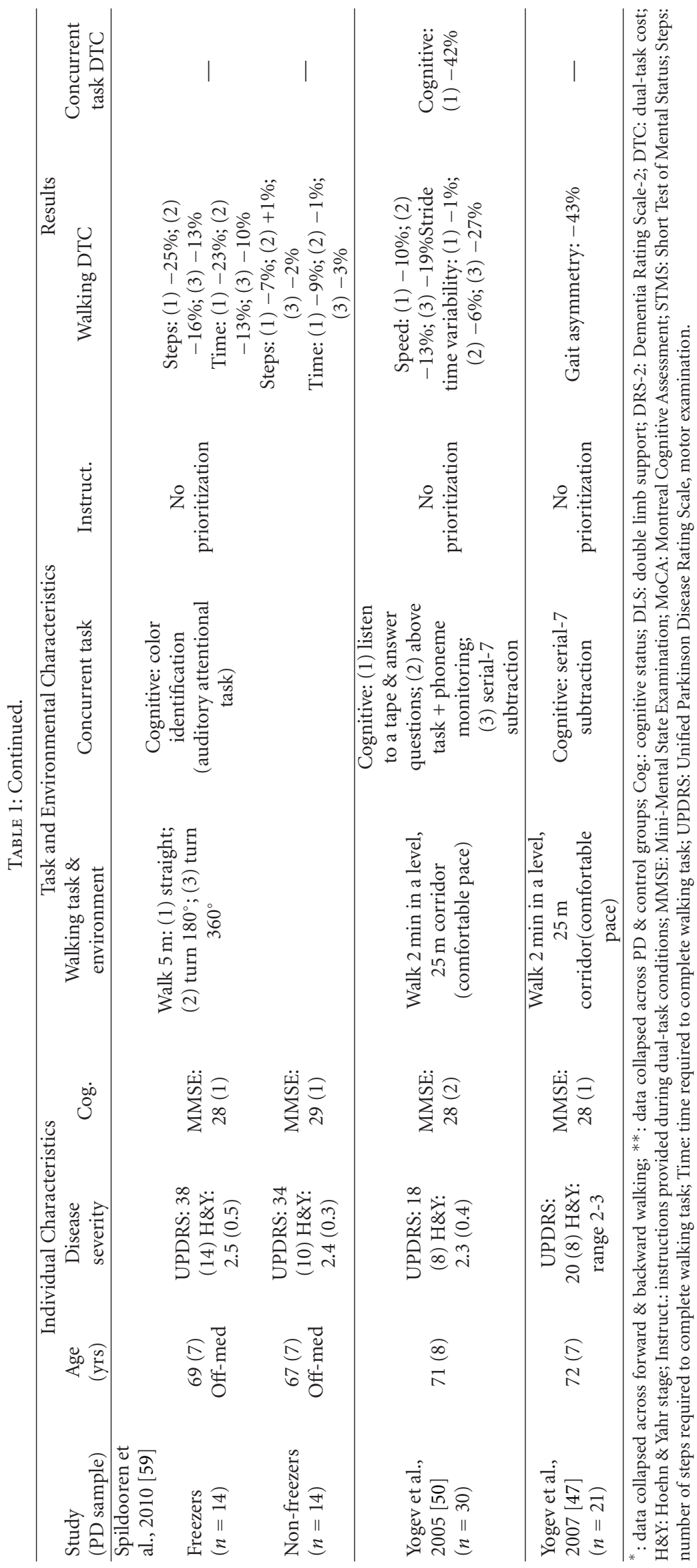


2.4. Environmental Factors. Studies that systematically manipulate environmental factors to determine the effects on dual-task walking deficits in PD are lacking. Most research was conducted in a clinical or laboratory environment, but some was conducted in participants' homes [43, 46, 57, 58]. Studies conducted in the home environment may be more representative of mobility challenges in daily life.

In summary, the literature as a whole confirms the presence of significant dual-task walking deficits among persons with $\mathrm{PD}$, despite methodological variations in participant characteristics, task demands, and environmental constraints. The extent of these deficits appears to vary as a function of individual, task, and environmental characteristics, but the relative contribution of each factor is not well understood. Carefully controlled studies are needed to better quantify how these factors impact dual-task walking deficits in people with $\mathrm{PD}$.

\section{Motor and Cognitive Factors Contributing to Dual-Task Walking Deficits}

3.1. Motor Factors. It is not clear how motor and cognitive symptoms contribute to either single-task or dual-task walking deficits in PD. The motor phenotype of $\mathrm{PD}$ is heterogeneous, with cardinal features of rigidity, tremor, and bradykinesia [64]. These symptoms, as well as primary impairments in locomotor control pathways [65], can contribute to both single- and dual-task gait abnormalities. The relative contributions of these factors may vary with disease progression. Cardinal symptoms may contribute more to walking deficits early in the disease, while primary gait impairments might predominate later in the disease.

Single-task walking deficits have been associated with a variety of motor symptoms in PD. For example, increased axial rigidity is associated with poorer performance on single-task measures of balance and functional mobility $[66,67]$. In addition, rigidity may contribute to reduced lower extremity joint excursions and a forward flexed posture when walking [39]. Bradykinesia can lead to shortened step length and reduced gait speed during walking [39]. Postural instability, another common motor symptom, may contribute to gait impairments such as increased stride-tostride variability and double limb support.

Several motor factors are associated with dual-task walking deficits in PD. Dual-task gait speed has been associated with disease severity, as measured by Hoehn and Yahr stage [46] and UPDRS motor subscale scores [43]. The severity of PD motor symptoms has also been related to single- and dual-task gait variability both off and on medication [57]. Dual-task walking performance in people with PD has been associated with performance-based measures of balance [46]. Though not a specific motor symptom of PD, some [46], but not all $[43,57]$, studies have found associations between physical fatigue and dual-task walking deficits in PD. Dualtask walking deficits in PD are also associated with primary gait deficits. Dual-task changes in speed and stride length were associated with performance on single-task mobility tests in people with PD [45]. In addition, dual-task walking deficits were greater in people with $\mathrm{PD}$ and freezing of gait compared to those without freezing $[53,55,59]$. Although dual-task walking deficits have been associated with both motor symptom severity and primary gait impairments, the relative contribution of each to dual-task walking deficits has not been well quantified.

3.2. Cognitive Factors. $\mathrm{PD}$ is associated with a variety of cognitive impairments, including executive function, attention, memory, language, and visuospatial impairments [68-70], that could contribute to dual-task walking deficits. Cognitive profiles in PD are variable [71] and range from mild deficits in specific cognitive domains to severe dementia affecting multiple domains. It is estimated that $19-30 \%$ of people with early, newly-diagnosed PD present with cognitive impairments [72-74], and these impairments worsen with disease progression [69]. The presence of mild cognitive impairment in people with $\mathrm{PD}$ is associated with development of dementia within 4 years [75]. The prevalence of dementia in $\mathrm{PD}$ is estimated at $26-44 \%[76,77]$, with over $80 \%$ of people developing dementia within 20 years of diagnosis [13]. Depression can exacerbate cognitive impairments in $\mathrm{PD}$ [78], and the frequency of depression in PD is estimated at $25-33 \%[79,80]$.

Specific cognitive functions, such as set shifting, divided or alternating attention, and response inhibition, may be particularly relevant to dual-task walking [28]. Dual-task walking deficits in PD have been associated with impairments in executive function, set-shifting, and attention [43, 45, 46]. For example, Plotnik and colleagues [45] demonstrated a relationship between set shifting, as measured by the Trail Making Test, and dual-task changes in gait speed and step length. Dual-task changes in gait variability were related to executive function, including set shifting and global cognition $[45,50,57]$. Executive function, measured by the Brixton test, has also been associated with gait speed [46] and gait speed DTCs [43]. Deficits in attention were associated with greater deficits in gait variability [57] and increased gait speed DTCs [43]. Finally, depression has been related to gait speed declines and gait variability increases under dual-task conditions in some studies $[46,57]$, though associations between dual-task parameters and affect (both depression and anxiety) were not supported by all studies [45].

Cognitive impairments can contribute to dual-task walking deficits in various ways. First, they may limit the ability to compensate for gait impairments using cognitive strategies. People with PD are often taught conscious strategies to improve their gait pattern, such as focusing on walking with longer steps. The type and severity of cognitive impairments may limit the ability to use such strategies to compensate for gait abnormalities. Also, impaired executive function might result in the inappropriate or unsafe prioritization of tasks when walking under dual-task conditions. Bloem and colleagues have proposed that increased fall risk in people with PD may result in part from a "posture second" prioritization strategy, in which concurrent tasks are prioritized above walking [81, 82]. Consistent with this idea, falls in 
PD have been associated with reduced performance on a variety of cognitive measures $[83,84]$. The prevalence of cognitive impairments in PD and their associations with dual-task walking deficits suggest that they are an important contributing factor. Further research is needed, however, because little is known about how the domains and severity of cognitive impairments affect dual-task walking deficits and their response to therapeutic interventions.

\section{Potential Mechanisms Underlying Dual-Task Walking Deficits}

The mechanisms responsible for interference between walking and concurrent cognitive or motor tasks in people with PD are not clear. Because multiple factors contribute to dual-task walking deficits, it is likely that a number of different mechanisms contribute to these deficits. In addition, characteristics of the concurrent task, such as type, domain, and difficulty, will impact the mechanisms and resources involved in dual-task performance. This section will review both nonspecific mechanisms proposed to explain dual-task interference across populations as well as specific mechanisms that may contribute to dual-task walking deficits in PD.

4.1. Nonspecific Mechanisms. Two general theoretical frameworks have been proposed to explain dual-task interference. Capacity theory conceptualizes the information processing needed for dual-task performance as a flexible but limited resource [27, 85, 86]. Performance of any given task, like walking, requires some portion of this capacity. When two tasks are performed concurrently, competition for limited resources results in dual-task interference and deterioration in performance of one or both tasks [26]. According to this theory, information processing resources such as attention can be flexibly allocated between tasks, with many factors potentially influencing resource allocation [86]. For example, differences in dual-task performance can result from individual differences in overall capacity, and intra-individual variability in dual-task performance can arise from transient variations in effective capacity due to factors like motivation, fatigue, or arousal [86]. Task-related factors also influence resource allocation. For example, a recent meta-analysis demonstrated that dual-task gait speed declines varied as a function of the concurrent cognitive task in healthy young and older adults and a general neurologic population [29].

A second general theory to explain dual-task interference is the bottleneck theory [87]. According to this theory, dualtask performance requires serial or sequential processing of the two concurrent tasks. Dual-task interference results when two tasks compete for the same processing resources. In order to complete one task, processing of the second task is temporarily postponed, resulting in performance decrements in the second task. Dual-task walking studies are limited in their ability to discriminate between these two theories, but these general mechanisms may inform methodological choices and subsequent interpretations.
4.2. PD-Specific Mechanisms. Several mechanisms specific to PD may also contribute to dual-task walking deficits. These mechanisms are not mutually exclusive, but might overlap with one another. Consistent with the capacity theory, a first specific mechanism in people with $\mathrm{PD}$ is reduced movement automaticity. Automaticity refers to the ability to perform a skilled movement without conscious or executive control or attention directed toward the movement $[88,89]$. The control of standing and walking was previously thought to be automatic, but the role of cognitive and executive functions in postural control is increasingly appreciated $[26,28]$. For example, in healthy young and older adults, simple reaction times increased when walking compared to sitting, reflecting greater attentional demands for walking $[90,91]$. The basal ganglia are proposed to play a role in the automatic control of movement [65]. In people with PD, basal ganglia dysfunction may lead to reduced movement automaticity and the need for increased reliance on cognitive resources to control movements. During dual-task upper extremity movements, people with PD demonstrated greater levels of activity in premotor and prefrontal cortical areas compared to healthy individuals, as measured by functional magnetic resonance imaging [92]. Similarly, people with PD may rely on greater cognitive control during walking, even under single-task conditions $[37,93]$. If reduced movement automaticity contributes to dual-task walking deficits in people with $\mathrm{PD}$, rehabilitation strategies designed to improve the automatic control of walking should improve dual-task walking.

A second mechanism that could contribute to dual-task walking deficits in PD is dopamine-mediated dysfunction of the basal ganglia. Multiple parallel pathways through the basal ganglia subserve different functions, including motor, cognitive, and limbic functions [94-96]. Degeneration of dopaminergic neurons in PD appears to affect both motor and cognitive circuits within the basal ganglia. Pathology of basal ganglia circuits that project to the dorsolateral prefrontal cortex may contribute to the executive function deficits that are prominent in people with $\operatorname{PD}[97,98]$. For example, specific deficits in set shifting, which are associated with dual-task walking deficits in PD [45], are thought to be mediated by the dorsolateral prefrontal cortex [98]. Dual-task walking deficits are improved by anti-parkinson medications $[53,57]$, supporting the idea that motor and cognitive impairments are due in part to dopaminergic pathways. However, the impact of anti-parkinson medications may be limited to those impairments mediated by dopamine dysfunction, and many studies demonstrate dualtask walking deficits in people with PD in the on-medication state.

A third mechanism that could contribute to dual-task walking deficits in PD is the presence of nondopaminergic pathology, which may affect both gait and cognition. It is increasingly appreciated that the pathology of PD is not limited to dopamine but includes other neurotransmitter systems, such as serotonin, norepinephrine (noradrenaline), or acetylcholine $[71,99,100]$. Dysfunction in multiple neurotransmitter systems may contribute to gait $[101,102]$ and cognitive impairments in PD [71]. Thus, non-dopaminergic 
pathways may also contribute to dual-task walking deficits in PD. Consistent with this idea, dual-task walking deficits persist even when people with $\mathrm{PD}$ are optimally medicated [42, 44, 50, 54, 59].

In summary, research suggests a number of general and specific mechanisms that may contribute to dualtask walking deficits in PD. These mechanisms are not mutually exclusive, and the relative contribution of each may depend on factors like the symptom profile of the individual and the specific task combination performed under dualtask conditions. A better understanding of the mechanisms responsible for dual-task walking deficits in PD can inform novel therapeutic approaches and enhance our ability to identify optimal interventions.

\section{Therapeutic Interventions: Impact on Dual-Task Walking Deficits}

The effects of various interventions on single-task walking in PD have been well described, but there is less research examining the efficacy of different pharmacological, surgical, or rehabilitative therapies on dual-task walking in this population. Because gait impairments in $\mathrm{PD}$ are exacerbated by dual-task conditions, which are common in daily life, it is important to understand how various therapeutic interventions affect dual-task walking.

5.1. Pharmacological Interventions. The reported effects of anti-parkinson medications on walking in PD are variable, even under single-task conditions. Medications improve aspects of single-task walking, including gait speed and stride length, but may not influence others, like stride-to-stride variability [38, 103, 104], festination, and freezing of gait $[39,105,106]$. As noted above, anti-parkinson medications increase speed and decrease variability during dual-task walking in PD [57] and even increase dual-task walking speed in those with freezing [53]. Neither of the above studies examined the effects of medication on concurrent task performance, so it is unclear if medication-related improvements were due to trade-offs between walking and the concurrent task. Medications can have limited or adverse effects on cognitive functions like set shifting [107] and certain types of learning $[108,109]$ that are critical to dual-task walking. As a result, medications could negatively affect dualtask walking or result in dual-task walking improvements at the expense of concurrent cognitive task performance. The positive effects of anti-parkinson medications on dual-task walking are consistent with a contribution from dopaminergic mechanisms, but persistent deficits in the on-medication state suggest that non-dopaminergic mechanisms may also contribute to dual-task interference.

5.2. Surgical Interventions. The reported effects of surgery on single-task walking are inconsistent. For example, initial improvements in postural control and gait as a result of deep brain stimulation are not sustained beyond 2-9 years [110]. In the short term, subthalamic nucleus stimulation can improve single-task gait speed and stride length, particularly in the off-medication condition $[111,112]$, but the individual response to subthalamic nucleus stimulation in the on-medication state is variable [113]. To date, no research has examined the effects of deep brain stimulation or ablative surgeries on dual-task walking in people with PD. The limited research on dual-task upper extremity movements is equivocal, with one study showing no effect of subthalamic nucleus stimulation [114] and one showing a decline [115].

5.3. Rehabilitation Interventions. There is considerable research demonstrating training-related improvements in single-task walking in persons with PD [116-122]. However, it is not clear whether dual-task walking deficits can be improved with practice in PD or, alternatively, whether clinicians should teach people with PD to avoid dual-task conditions to improve safety [123]. A variety of rehabilitation strategies to improve dual-task walking in PD have been studied, with most research focusing on external cues, cognitive or attentional strategies, and dual-task gait training.

External visual, auditory, or somatosensory cues improve both single- and dual-task walking in PD [42, 124-129], even among those with de novo PD [130] or cognitive impairment [131]. For example, Rochester and colleagues examined the effects of external rhythmic cues (auditory, visual, and somatosensory) on walking in people with $\mathrm{PD}$ [128]. Cueing therapy was provided over nine 30-minute sessions in the home and consisted of training during singleand dual-task walking and during various functional walking tasks. Speed and step length improved during both singleand dual-task cued walking conditions. These improvements transferred to noncued walking and were retained at 6week follow-up testing. The authors suggest that dualtask walking improvements were likely due to improved walking automaticity. Based on this research, external cueing appears to improve walking under both single- and dualtask conditions in people with PD. However, studies of cue training vary in terms of cueing modality, training duration, tests used for outcomes assessment, and length of followup. Further research is needed to determine the parameters of cue training that provide the greatest and most sustained benefits for dual-task walking in PD.

Cognitive or attentional strategies (e.g., focusing attention on walking with long steps) can also improve walking in people with PD $[125,126,132]$, but evidence for the efficacy of cognitive strategies to improve dual-task walking is mixed. Dual-task conditions introduce a concurrent task requiring cognitive control. As suggested by the capacity theory of dual-task interference, the need to direct cognitive resources to the concurrent task may limit the ability to use conscious or unconscious cognitive control to improve walking in PD. Some studies indicate that attention can improve dual-task walking [125], while others find that attentional strategies are not effective under dual-task conditions [133].

Recent intervention studies have combined dual-task gait training with cognitive strategies to direct attentional focus and task prioritization. Even people with early PD report the need to monitor and consciously correct walking 
deficits [93]. However, research suggests that people with PD prioritize concurrent tasks over postural tasks under dual task conditions, thereby decreasing safety and increasing fall risk [82]. A number of intervention studies have examined the effects of dual-task training with various instructions regarding task prioritization. Training with instructions to prioritize walking improved gait velocity and stride length under both single- and dual-task conditions [125, 134], with retention at 30 minutes [134]. Dual-task training with instructions to divide attention equally between walking and the concurrent cognitive task also improved dual-task gait speed and stride length, with retention at 30 minutes [135]. However, the same concurrent task was used for both training and outcomes measurement in this study, so it is not clear if these training-related improvements generalize to other dual-task combinations. Canning and colleagues also examined multitask training with divided attention instructions [136]. In this study, the concurrent tasks used during training differed from those used for outcomes measurement. Training improved gait speed and cadence, with improvements retained at 3-week follow-up. Finally, Brauer and Morris examined the effects of dual-task training using variable-priority instructions, where prioritization is shifted between walking and the concurrent task [137]. Gait speed and step length improved for both the trained dual-task combinations and on novel dual-task walking combinations. Performance on the concurrent tasks did not decline, indicating that dual-task walking improvements were not due to between-task trade-offs. The authors suggest that practice may reduce the attentional demands of walking and increase automaticity, thus enabling individuals with PD to attend to more challenging concurrent tasks. Together, these studies suggest that dual-task gait training is an effective intervention, but the relative impact of different instructional sets requires further research.

One of the limitations in the research on dual-task walking interventions is the lack of consistent and validated measures of dual-task walking performance. Appropriate outcome measures are necessary to determine if a person with PD has dual-task walking deficits and if a given intervention effectively improves these deficits. A variety of tests, including the Stops Walking When Talking test or the Walking and Remembering Test, have been used to assess dual-task walking performance in older adults [138144]. Few of these measures have been examined in the PD population $[54,81,145]$, thus the psychometric properties of these tests in PD are unclear. Future research is needed to determine reliable, valid, and sensitive outcome measures to evaluate dual-task walking performance in people with PD and quantify the response to different interventions.

Research supports the efficacy of rehabilitative interventions, including external cueing, cognitive strategies, and dual-task gait training, to improve dual-task walking deficits in PD. Emerging research is examining additional treatment approaches to improve dual-task walking. For example, treadmill training with virtual reality, designed to incorporate more complex task and environmental conditions, has been shown to improve both single- and dualtask walking in people with PD [146]. Future research is needed to examine optimal treatment parameters for both established and novel dual-task walking interventions, the relative efficacy of different interventions, whether dualtask walking improvements generalize to novel dual-task combinations, and the degree to which improvements in dual-task walking are retained.

\section{Summary}

This paper has reviewed basic and applied research related to dual-task walking deficits in people with PD. Gait impairments under both single-task and dual-task conditions are prevalent in people with PD and are associated with serious consequences. The severity of dual-task walking deficits appears to vary as a function of individual, task, and environmental characteristics, though the relative impacts of each factor are not well understood. Both motor and cognitive impairments have been associated with dual-task walking deficits in persons with PD. However, because the clinical profile of $\mathrm{PD}$ is heterogeneous, further research is needed to elucidate the relative contributions of each of these impairments to dual-task walking deficits. A number of general and specific mechanisms may underlie dual-task walking deficits in PD. The role of each is not clear, but might depend on the dual-task combination performed. These mechanisms inform a number of therapeutic interventions. Rehabilitation interventions, including external cues, cognitive strategies, and dual-task gait training, appear to be effective in reducing dual-task walking deficits in PD. However, a better understanding of the individual, task, and environmental factors that influence dual-task walking deficits is critical to refine existing interventions and identify novel therapeutic approaches.

\section{Acknowledgment}

This work was supported by the National Institutes of Health, National Institute of Child Health and Human Development (K01HD052018).

\section{References}

[1] G. A. Kang, J. M. Bronstein, D. L. Masterman, M. Redelings, J. A. Crum, and B. Ritz, "Clinical characteristics in early Parkinson's disease in a central California population-based study," Movement Disorders, vol. 20, no. 9, pp. 1133-1142, 2005.

[2] D. Muslimović, B. Post, J. D. Speelman, B. Schmand, and R. J. de Haan, "Determinants of disability and quality of life in mild to moderate Parkinson disease," Neurology, vol. 70, no. 23, pp. 2241-2247, 2008.

[3] B. Post, M. P. Merkus, R. J. de Haan, and J. D. Speelman, "Prognostic factors for the progression of Parkinson's disease: a systematic review," Movement Disorders, vol. 22, no. 13, pp. 1839-1851, 2007.

[4] W. C. Koller, S. Glatt, B. Vetere-Overfield, and R. Hassanein, "Falls and Parkinson's disease," Clinical Neuropharmacology, vol. 12, no. 2, pp. 98-105, 1989.

[5] P. Gray and K. Hildebrand, "Fall risk factors in Parkinson's disease," The Journal of Neuroscience Nursing, vol. 32, no. 4, pp. 222-228, 2000. 
[6] C. L. Wielinski, C. Erickson-Davis, R. Wichmann, M. WaldeDouglas, and S. A. Parashos, "Falls and injuries resulting from falls among patients with Parkinson's disease and other Parkinsonian syndromes," Movement Disorders, vol. 20, no. 4, pp. 410-415, 2005.

[7] H. Woodford and R. Walker, "Emergency hospital admissions in idiopathic's Parkinson's disease," Movement Disorders, vol. 20, no. 9, pp. 1104-1108, 2005.

[8] R. W. Genever, T. W. Downes, and P. Medcalf, "Fracture rates in Parkinson's disease compared with age- and gendermatched controls: a retrospective cohort study," Age and Ageing, vol. 34, no. 1, pp. 21-24, 2005.

[9] L. J. Melton, C. L. Leibson, S. J. Achenbach et al., "Fracture risk after the diagnosis of Parkinson's disease: influence of concomitant dementia," Movement Disorders, vol. 21, no. 9, pp. 1361-1367, 2006.

[10] P. Vestergaard, L. Rejnmark, and L. Mosekilde, "Fracture risk associated with parkinsonism and anti-Parkinson drugs," Calcified Tissue International, vol. 81, no. 3, pp. 153-161, 2007.

[11] A. Ashburn, E. Stack, R. M. Pickering, and C. D. Ward, "A community-dwelling sample of people with Parkinson's disesase: characteristics of fallers and non-fallers," Age and Ageing, vol. 30, no. 1, pp. 47-52, 2001.

[12] B. R. Bloem, Y. A. M. Grimbergen, M. Cramer, M. Willemsen, and A. H. Zwinderman, "Prospective assessment of falls in Parkinson's disease," Journal of Neurology, vol. 248, no. 11, pp. 950-958, 2001.

[13] M. A. Hely, W. G. J. Reid, M. A. Adena, G. M. Halliday, and J. G. L. Morris, "The Sydney Multicenter Study of Parkinson's disease: the inevitability of dementia at 20 years," Movement Disorders, vol. 23, no. 6, pp. 837-844, 2008.

[14] G. K. Kerr, C. J. Worringham, M. H. Cole, P. F. Lacherez, J. M. Wood, and P. A. Silburn, "Predictors of future falls in Parkinson disease,” Neurology, vol. 75, no. 2, pp. 116-124, 2010.

[15] R. M. Pickering, Y. A. M. Grimbergen, U. Rigney et al., "A meta-analysis of six prospective studies of falling in Parkinson's disease," Movement Disorders, vol. 22, no. 13, pp. 1892-1900, 2007.

[16] B. H. Wood, J. A. Bilclough, A. Bowron, and R. W. Walker, "Incidence and prediction of falls in Parkinson's disease: a prospective multidisciplinary study," Journal of Neurology Neurosurgery and Psychiatry, vol. 72, no. 6, pp. 721-725, 2002.

[17] A. Ashburn, E. Stack, C. Ballinger, L. Fazakarley, and C. Fitton, "The circumstances of falls among people with Parkinson's disease and the use of Falls Diaries to facilitate reporting," Disability and Rehabilitation, vol. 30, no. 16, pp. 1205-1212, 2008.

[18] L. E. Dibble, J. Christensen, D. J. Ballard, and K. B. Foreman, "Diagnosis of fall risk in Parkinson disease: an analysis of individual and collective clinical balance test interpretation," Physical Therapy, vol. 88, no. 3, pp. 323-332, 2008.

[19] A. C. Dennison, J. V. Noorigian, K. M. Robinson et al., "Falling in Parkinson disease: identifying and prioritizing risk factors in recurrent fallers," American Journal of Physical Medicine and Rehabilitation, vol. 86, no. 8, pp. 621-632, 2007.

[20] J. C. Gómez-Esteban, J. J. Zarranz, E. Lezcano et al., "Influence of motor symptoms upon the quality of life of patients with Parkinson's disease," European Neurology, vol. 57, no. 3, pp. 161-165, 2007.
[21] K. E. Lyons, R. Pahwa, A. I. Tröster, and W. C. Koller, "A comparison of Parkinson's disease symptoms and selfreported functioning and well being," Parkinsonism and Related Disorders, vol. 3, no. 4, pp. 207-209, 1997.

[22] O. Moore, C. Peretz, and N. Giladi, "Freezing of gait affects quality of life of peoples with Parkinson's disease beyond its relationships with mobility and gait," Movement Disorders, vol. 22, no. 15, pp. 2192-2195, 2007.

[23] R. Shibley, H. J. Griffin, N. P. Quinn, and M. Jahanshahi, "Quality of life in Parkinson's disease: the relative importance of the symptoms," Movement Disorders, vol. 23, no. 10, pp. 1428-1434, 2008.

[24] S. E. Soh, M. E. Morris, and J. L. McGinley, "Determinants of health-related quality of life in Parkinson's disease: a systematic review," Parkinsonism and Related Disorders, vol. 19, no. 1, pp. 1-9, 2011.

[25] M. Schenkman, T. M. Cutson, C. W. Zhu, and K. WhettenGoldstein, "A longitudinal evaluation of patients' perceptions of Parkinson's disease," Gerontologist, vol. 42, no. 6, pp. 790798, 2002.

[26] M. Woollacott and A. Shumway-Cook, "Attention and the control of posture and gait: a review of an emerging area of research," Gait and Posture, vol. 16, no. 1, pp. 1-14, 2002.

[27] E. V. Fraizer and S. Mitra, "Methodological and interpretive issues in posture-cognition dual-tasking in upright stance," Gait and Posture, vol. 27, no. 2, pp. 271-279, 2008.

[28] G. Yogev-Seligmann, J. M. Hausdorff, and N. Giladi, "The role of executive function and attention in gait," Movement Disorders, vol. 23, no. 3, pp. 329-342, 2008.

[29] E. Al-Yahya, H. Dawes, L. Smith, A. Dennis, K. Howells, and J. Cockburn, "Cognitive motor interference while walking: a systematic review and meta-analysis," Neuroscience and Biobehavioral Reviews, vol. 35, no. 3, pp. 715-728, 2011.

[30] C. Dromey, E. Jarvis, S. Sondrup, S. Nissen, K. B. Foreman, and L. E. Dibble, "Bidirectional interference between speech and postural stability in individuals with Parkinson's disease," International Journal of Speech-Language Pathology, vol. 12, no. 5, pp. 446-454, 2010.

[31] R. Marchese, M. Bove, and G. Abbruzzese, "Effect of cognitive and motor tasks on postural stability in Parkinson's disease: a posturographic study," Movement Disorders, vol. 18, no. 6, pp. 652-658, 2003.

[32] S. D. Pradhan, B. R. Brewer, G. E. Carvell, P. J. Sparto, A. Delitto, and Y. Matsuoka, "Assessment of fine motor control in individuals with Parkinson's disease using force tracking with a secondary cognitive task," Journal of Neurologic Physical Therapy, vol. 34, no. 1, pp. 32-40, 2010.

[33] E. L. Proud and M. E. Morris, "killed hand dexterity in Parkinson's disease: effects of adding a concurrent task," Archives of Physical Medicine and Rehabilitation, vol. 91, no. 5, pp. 794-799, 2010.

[34] A. K. Ho, R. Iansek, and J. L. Bradshaw, "The effect of a concurrent task on Parkinsonian speech," Journal of Clinical and Experimental Neuropsychology, vol. 24, no. 1, pp. 36-47, 2002.

[35] O. Blin, A. M. Ferrandez, and G. Serratrice, "Quantitative analysis of gait in Parkinson patients: increased variability of stride length," Journal of the Neurological Sciences, vol. 98, no. 1, pp. 91-97, 1990.

[36] J. M. Hausdorff, M. E. Cudkowicz, R. Firtion, J. Y. Wei, and A. L. Goldberger, "Gait variability and basal ganglia disorders: stride-to-stride variations of gait cycle timing in Parkinson's disease and Huntington's disease," Movement Disorders, vol. 13, no. 3, pp. 428-437, 1998. 
[37] M. E. Morris, R. Iansek, T. A. Matyas, and J. J. Summers, "The pathogenesis of gait hypokinesia in Parkinson's disease," Brain, vol. 117, no. 5, part 5, pp. 1169-1181, 1994.

[38] J. D. O'Sullivan, C. M. Said, L. C. Dillon, M. Huffman, and A. J. Hughes, "Gait analysis in patients with Parkinson's disease and motor fluctuations: influence of levodopa and comparison with other measures of motor function," Movement Disorders, vol. 13, no. 6, pp. 900-906, 1998.

[39] N. Giladi, "Gait disturbances in advanced stages of Parkinson's disease," Advances in Neurology, vol. 86, pp. 273-278, 2001.

[40] J. M. Bond and M. Morn's, "Goal-directed secondary motor tasks: their effects on gait in subjects with Parkinson disease," Archives of Physical Medicine and Rehabilitation, vol. 81, no. 1, pp. 110-116, 2000.

[41] L. A. Brown, N. de Bruin, J. B. Doan, O. Suchowersky, and B. Hu, "Novel challenges to gait in Parkinson's disease: the effect of concurrent music in single- and dual-task contexts," Archives of Physical Medicine and Rehabilitation, vol. 90, no. 9, pp. 1578-1583, 2009.

[42] R. Galletly and S. G. Brauer, "Does the type of concurrent task affect preferred and cued gait in people with Parkinson's disease?" Australian Journal of Physiotherapy, vol. 51, no. 3, pp. 175-180, 2005.

[43] S. Lord, L. Rochester, V. Hetherington, L. M. Allcock, and D. Burn, "Executive dysfunction and attention contribute to gait interference in 'off' state Parkinson's Disease," Gait and Posture, vol. 31, no. 2, pp. 169-174, 2010.

[44] S. O'Shea, M. E. Morris, and R. Iansek, "Dual task interference during gait in people with Parkinson disease: effects of motor versus cognitive secondary tasks," Physical Therapy, vol. 82, no. 9, pp. 888-897, 2002.

[45] M. Plotnik, Y. Dagan, T. Gurevich, N. Giladi, and J. M. Hausdorff, "Effects of cognitive function on gait and dual tasking abilities in patients with Parkinson's disease suffering from motor response fluctuations," Experimental Brain Research, vol. 208, no. 2, pp. 169-179, 2011.

[46] L. Rochester, V. Hetherington, D. Jones et al., "Attending to the task: interference effects of functional tasks on walking in Parkinson's disease and the roles of cognition, depression, fatigue, and balance," Archives of Physical Medicine and Rehabilitation, vol. 85, no. 10, pp. 1578-1585, 2004.

[47] G. Yogev, M. Plotnik, C. Peretz, N. Giladi, and J. M. Hausdorff, "Gait asymmetry in patients with Parkinson's disease and elderly fallers: when does the bilateral coordination of gait require attention?" Experimental Brain Research, vol. 177, no. 3, pp. 336-346, 2007.

[48] M. Plotnik, N. Giladi, and J. M. Hausdorff, "Bilateral coordination of gait and Parkinson's disease: the effects of dual tasking," Journal of Neurology, Neurosurgery and Psychiatry, vol. 80, no. 3, pp. 347-350, 2009.

[49] J. M. Hausdorff, J. Balash, and N. Giladi, "Effects of cognitive challenge on gait variability in patients with Parkinson's disease," Journal of Geriatric Psychiatry and Neurology, vol. 16, no. 1, pp. 53-58, 2003.

[50] G. Yogev, N. Giladi, C. Peretz, S. Springer, E. S. Simon, and J. M. Hausdorff, "Dual tasking, gait rhythmicity, and Parkinson's disease: which aspects of gait are attention demanding?" European Journal of Neuroscience, vol. 22, no. 5, pp. 1248-1256, 2005.

[51] O. Bock, "Dual-task costs while walking increase in old age for some, but not for other tasks: an experimental study of healthy young and elderly persons," Journal of NeuroEngineering and Rehabilitation, vol. 5, article 27, 2008.
[52] M. Doumas, C. Smolders, and R. T. Krampe, "Task prioritization in aging: effects of sensory information on concurrent posture and memory performance," Experimental Brain Research, vol. 187, no. 2, pp. 275-281, 2008.

[53] R. Camicioli, B. S. Oken, G. Sexton, J. A. Kaye, and J. G. Nutt, "Verbal fluency task affects gait in Parkinson's disease with motor freezing," Journal of Geriatric Psychiatry and Neurology, vol. 11, no. 4, pp. 181-185, 1998.

[54] C. M. Campbell, J. L. Rowse, M. A. Ciol et al., "The effect of cognitive demand on Timed Up and Go performance in older adults with and without Parkinson disease," Neurology Report, vol. 27, no. 1, pp. 2-7, 2003.

[55] M. E. Hackney and G. M. Earhart, "The effects of a secondary task on forward and backward walking in Parkinson's disease," Neurorehabilitation and Neural Repair, vol. 24, no. 1, pp. 97-106, 2009.

[56] L. L. Lapointe, J. A. G. Stierwalt, and C. G. Maitland, "Talking while walking: cognitive loading and injurious falls in Parkinson's disease," International Journal of SpeechLanguage Pathology, vol. 12, no. 5, pp. 455-459, 2010.

[57] S. Lord, K. Baker, A. Nieuwboer et al., "Gait variability in Parkinson's disease: an indicator of non-dopaminergic contributors to gait dysfunction?" Journal of Neurology, vol. 258, no. 4, pp. 566-572, 2011.

[58] L. Rochester, A. Nieuwboer, K. Baker et al., "Walking speed during single and dual tasks in Parkinson's disease: which characteristics are important?" Movement Disorders, vol. 23, no. 16, pp. 2312-2318, 2008.

[59] J. Spildooren, S. Vercruysse, K. Desloovere, W. Vandenberghe, E. Kerckhofs, and A. Nieuwboer, "Freezing of gait in Parkinson's disease: the impact of dual-tasking and turning," Movement Disorders, vol. 25, no. 15, pp. 2563-2570, 2010.

[60] A. W. Priest, K. B. Salamon, and J. H. Hollman, "Age-related differences in dual task walking: a cross sectional study," Journal of NeuroEngineering and Rehabilitation, vol. 5, article 29, 2008.

[61] V. E. Kelly, M. A. Schrager, R. Price, L. Ferrucci, and A. Shumway-Cook, "Age-associated effects of a concurrent cognitive task on gait speed and stability during narrow-base walking," Journals of Gerontology, Series A, vol. 63, no. 12, pp. 1329-1334, 2008.

[62] M. Plotnik, N. Giladi, Y. Dagan, and J. M. Hausdorff, "Postural instability and fall risk in Parkinson's disease: impaired dual tasking, pacing, and bilateral coordination of gait during the "ON" medication state," Experimental Brain Research, vol. 210, no. 3-4, pp. 529-538, 2011.

[63] V. E. Kelly, A. A. Janke, and A. Shumway-Cook, "Effects of instructed focus and task difficulty on concurrent walking and cognitive task performance in healthy young adults," Experimental Brain Research, vol. 207, no. 1-2, pp. 65-73, 2010.

[64] A. Samii, J. G. Nutt, and B. R. Ransom, "Parkinson's disease," Lancet, vol. 363, no. 9423, pp. 1783-1793, 2004.

[65] K. Takakusaki, J. Oohinata-Sugimoto, K. Saitoh, and T. Habaguchi, "Role of basal ganglia-brainstem systems in the control of postural muscle tone and locomotion," Progress in Brain Research, vol. 143, pp. 231-237, 2004.

[66] E. Franzén, C. Paquette, V. S. Gurfinkel, P. J. Cordo, J. G. Nutt, and F. B. Horak, "Reduced performance in balance, walking and turning tasks is associated with increased neck tone in Parkinson's disease," Experimental Neurology, vol. 219, no. 2, pp. 430-438, 2009.

[67] M. Schenkman, M. Morey, and M. Kuchibhatla, "Spinal flexibility and balance control among community-dwelling 
adults with and without Parkinson's disease," Journals of Gerontology, Series A, vol. 55, no. 8, pp. M441-M445, 2000.

[68] D. Aarsland, K. Bronnick, C. Williams-Gray et al., "Mild cognitive impairment in Parkinson disease: a multicenter pooled analysis," Neurology, vol. 75, no. 12, pp. 1062-1069, 2010.

[69] D. Muslimović, B. Schmand, J. D. Speelman, and R. J. de Haan, "Course of cognitive decline in Parkinson's disease: a meta-analysis," Journal of the International Neuropsychological Society, vol. 13, no. 6, pp. 920-932, 2007.

[70] G. S. Watson and J. B. Leverenz, "Profile of cognitive impairment in parkinson's disease," Brain Pathology, vol. 20, no. 3, pp. 640-645, 2010.

[71] A. A. Kehagia, R. A. Barker, and T. W. Robbins, "Neuropsychological and clinical heterogeneity of cognitive impairment and dementia in patients with Parkinson's disease," The Lancet Neurology, vol. 9, no. 12, pp. 1200-1213, 2010.

[72] D. Aarsland, K. Brønnick, J. P. Larsen, O. B. Tysnes, and G. Alves, "Cognitive impairment in incident, untreated parkinson disease: the norwegian parkwest study," Neurology, vol. 72, no. 13, pp. 1121-1126, 2009.

[73] E. Elgh, M. Domellöf, J. Linder, M. Edström, H. Stenlund, and L. Forsgren, "Cognitive function in early Parkinson's disease: a population-based study," European Journal of Neurology, vol. 16, no. 12, pp. 1278-1284, 2009.

[74] D. Muslimović, B. Post, J. D. Speelman, and B. Schmand, "Cognitive profile of patients with newly diagnosed Parkinson disease," Neurology, vol. 65, no. 8, pp. 1239-1245, 2005.

[75] C. C. Janvin, J. P. Larsen, D. Aarsland, and K. Hugdahl, "Subtypes of mild cognitive impairment in Parkinson's disease: progression to dementia," Movement Disorders, vol. 21, no. 9, pp. 1343-1349, 2006.

[76] D. Aarsland, K. Andersen, J. P. Larsen, A. Lolk, and P. KraghSørensen, "Prevalence and characteristics of dementia in Parkinson disease: an 8-year prospective study," Archives of Neurology, vol. 60, no. 3, pp. 387-392, 2003.

[77] P. Hobson and J. Meara, "The detection of dementia and cognitive impairment in a community population of elderly people with Parkinson's disease by use of the CAMCOG neuropsychological test," Age and Ageing, vol. 28, no. 1, pp. 39-44, 1999.

[78] S. Norman, A. I. Tröster, J. A. Fields, and R. Brooks, "Effects of depression and Parkinson's disease on cognitive functioning," Journal of Neuropsychiatry and Clinical Neurosciences, vol. 14, no. 1, pp. 31-36, 2002.

[79] N. Giladi, T. A. Treves, D. Paleacu et al., "Risk factors for dementia, depression and psychosis in long-standing Parkinson's disease," Journal of Neural Transmission, vol. 107, no. 1, pp. 59-71, 2000.

[80] O. Riedel, J. Klotsche, A. Spottke et al., "Frequency of dementia, depression, and other neuropsychiatric symptoms in 1,449 outpatients with Parkinson's disease," Journal of Neurology, vol. 257, no. 7, pp. 1073-1082, 2010.

[81] B. R. Bloem, V. V. Valkenburg, M. Slabbekoorn, and J. G. van Dijk, "The multiple tasks test. Strategies in Parkinson's disease," Experimental Brain Research, vol. 137, no. 3-4, pp. 478-486, 2001.

[82] B. R. Bloem, Y. A. M. Grimbergen, J. G. van Dijk, and M. Munneke, "The "posture second" strategy: a review of wrong priorities in Parkinson's disease," Journal of the Neurological Sciences, vol. 248, no. 1-2, pp. 196-204, 2006.

[83] L. M. Allcock, E. N. Rowan, I. N. Steen, K. Wesnes, R. A. Kenny, and D. J. Burn, "Impaired attention predicts falling in Parkinson's disease," Parkinsonism and Related Disorders, vol. 15, no. 2, pp. 110-115, 2009.

[84] R. Camicioli and S. R. Majumdar, "Relationship between mild cognitive impairment and falls in older people with and without Parkinson's disease: 1-Year Prospective Cohort Study," Gait and Posture, vol. 32, no. 1, pp. 87-91, 2010.

[85] M. Tombu and P. Jolicoæur, "A central capacity sharing model of dual-task performance," Journal of Experimental Psychology: Human Perception and Performance, vol. 29, no. 1, pp. 3-18, 2003.

[86] B. Abernethy, "Dual-task methodology and motor skills research: some applications and methodological constraints," Journal of Human Movement Studies, vol. 14, no. 3, pp. 101132, 1988.

[87] E. Ruthruff, H. E. Pashler, and A. Klaassen, "Processing bottlenecks in dual-task performance: structural limitation or strategic postponement?" Psychonomic Bulletin and Review, vol. 8, no. 1, pp. 73-80, 2001.

[88] R. A. Poldrack, F. W. Sabb, K. Foerde et al., "The neural correlates of motor skill automaticity," Journal of Neuroscience, vol. 25, no. 22, pp. 5356-5364, 2005.

[89] T. Wu, K. Kansaku, and M. Hallett, "How self-initiated memorized movements become automatic: a functional MRI study," Journal of Neurophysiology, vol. 91, no. 4, pp. 16901698, 2004.

[90] Y. Lajoie, N. Teasdale, C. Bard, and M. Fleury, "Attentional demands for static and dynamic equilibrium," Experimental Brain Research, vol. 97, no. 1, pp. 139-144, 1993.

[91] Y. Lajoie, N. Teasdale, C. Bard, and M. Fleury, "Upright standing and gait: are there changes in attentional requirements related to normal aging?" Experimental Aging Research, vol. 22, no. 2, pp. 185-198, 1996.

[92] T. Wu and M. Hallett, "Neural correlates of dual task performance in patients with Parkinson's disease," Journal of Neurology, Neurosurgery and Psychiatry, vol. 79, no. 7, pp. 760-766, 2008.

[93] D. Jones, L. Rochester, A. Birleson et al., "Everyday walking with Parkinson's disease: understanding personal challenges and strategies," Disability and Rehabilitation, vol. 30, no. 16, pp. 1213-1221, 2008.

[94] G. E. Alexander, M. R. DeLong, and P. L. Strick, "Parallel organization of functionally segregated circuits linking basal ganglia and cortex," Annual Review of Neuroscience, vol. 9, pp. 357-381, 1986.

[95] F. A. Middleton and P. L. Strick, "Anatomical evidence for cerebellar and basal ganglia involvement in higher cognitive function," Science, vol. 266, no. 5184, pp. 458-461, 1994.

[96] F. A. Middleton and P. L. Strick, "Basal ganglia output and cognition: evidence from anatomical, behavioral, and clinical studies," Brain and Cognition, vol. 42, no. 2, pp. 183-200, 2000.

[97] D. J. Zgaljardic, J. C. Borod, N. S. Foldi, and P. Mattis, "A review of the cognitive and behavioral sequelae of Parkinson's disease: relationship to frontostriatal circuitry," Cognitive and Behavioral Neurology, vol. 16, no. 4, pp. 193-210, 2003.

[98] D. J. Zgaljardic, J. C. Borod, N. S. Foldi et al., "An examination of executive dysfunction associated with frontostriatal circuitry in Parkinson's disease," Journal of Clinical and Experimental Neuropsychology, vol. 28, no. 7, pp. 1127-1144, 2006.

[99] P. Barone, "Neurotransmission in Parkinson's disease: beyond dopamine," European Journal of Neurology, vol. 17, no. 3, pp. 364-376, 2010. 
[100] J. B. Leverenz, J. F. Quinn, C. Zabetian, J. Zhang, K. S. Montine, and T. J. Montine, "Cognitive impairment and dementia in patients with Parkinson disease," Current Topics in Medicinal Chemistry, vol. 9, no. 10, pp. 903-912, 2009.

[101] D. Devos, L. Defebvre, and R. Bordet, "Dopaminergic and non-dopaminergic pharmacological hypotheses for gait disorders in Parkinson's disease," Fundamental and Clinical Pharmacology, vol. 24, no. 4, pp. 407-421, 2010.

[102] C. Karachi, D. Grabli, F. A. Bernard et al., "Cholinergic mesencephalic neurons are involved in gait and postural disorders in Parkinson disease," Journal of Clinical Investigation, vol. 120, no. 8, pp. 2745-2754, 2010.

[103] O. Blin, A. M. Ferrandez, J. Pailhous, and G. Serratrice, "Dopa-sensitive and Dopa resistant gait parameters in Parkinson's disease," Journal of the Neurological Sciences, vol. 103, no. 1, pp. 51-54, 1991.

[104] J. D. Schaafsma, N. Giladi, Y. Balash, A. L. Bartels, T. Gurevich, and J. M. Hausdorff, "Gait dynamics in Parkinson's disease: relationship to Parkinsonian features, falls and response to levodopa," Journal of the Neurological Sciences, vol. 212, no. 1-2, pp. 47-53, 2003.

[105] I. C. López, P. J. G. Ruiz, S. V. F. del Pozo, and V. S. Bernardos, "Motor complications in Parkinson's disease: ten year followup study," Movement Disorders, vol. 25, no. 16, pp. 2735 2739, 2010.

[106] P. J. García Ruiz, E. Meseguer, J. del Val, A. Vázquez, V. Sanchez Bernardos, and A. Vázquez, "Motor complications in Parkinson disease: a prospective follow-up study," Clinical Neuropharmacology, vol. 27, no. 2, pp. 49-52, 2004.

[107] S. J. G. Lewis, A. Slabosz, T. W. Robbins, R. A. Barker, and A. M. Owen, "Dopaminergic basis for deficits in working memory but not attentional set-shifting in Parkinson's disease," Neuropsychologia, vol. 43, no. 6, pp. 823-832, 2005.

[108] R. Cools, R. A. Barker, B. J. Sahakian, and T. W. Robbins, "Enhanced or impaired cognitive function in Parkinson's disease as a function of dopaminergic medication and task demands," Cerebral Cortex, vol. 11, no. 12, pp. 1136-1143, 2001.

[109] M. Jahanshahi, L. Wilkinson, H. Gahir, A. Dharminda, and D. A. Lagnado, "Medication impairs probabilistic classification learning in Parkinson's disease," Neuropsychologia, vol. 48, no. 4, pp. 1096-1103, 2010.

[110] R. J. S. George, J. G. Nutt, K. J. Burchiel, and F. B. Horak, "A meta-regression of the long-term effects of deep brain stimulation on balance and gait in PD," Neurology, vol. 75, no. 14, pp. 1292-1299, 2010.

[111] A. J. Bastian, V. E. Kelly, F. J. Revilla, J. S. Perlmutter, and J. W. Mink, "Different effects of unilateral versus bilateral subthalamic nucleus stimulation on walking and reaching in Parkinson's disease," Movement Disorders, vol. 18, no. 9, pp. 1000-1007, 2003.

[112] M. Faist, J. Xie, D. Kurz et al., "Effect of bilateral subthalamic nucleus stimulation on gait in Parkinson's disease," Brain, vol. 124, part 8, pp. 1590-1600, 2001.

[113] V. E. Kelly, A. Samii, J. C. Slimp, R. Price, R. Goodkin, and A. Shumway-Cook, "Gait changes in response to subthalamic nucleus stimulation in people with Parkinson disease: a case series report," Journal of Neurologic Physical Therapy, vol. 30, no. 4, pp. 184-194, 2006.

[114] D. Page and M. Jahanshahi, "Deep brain stimulation of the subthalamic nucleus improves set shifting but does not affect dual task performance in Parkinson's disease," IEEE Transactions on Neural Systems and Rehabilitation Engineering, vol. 15, no. 2, pp. 198-206, 2007.
[115] J. L. Alberts, C. Voelcker-Rehage, K. Hallahan, M. Vitek, R. Bamzai, and J. L. Vitek, "Bilateral subthalamic stimulation impairs cognitive-motor performance in Parkinson's disease patients," Brain, vol. 131, part 12, pp. 3348-3360, 2008.

[116] L. E. Dibble, T. F. Hale, R. L. Marcus, J. Droge, J. P. Gerber, and P. C. LaStayo, "High-intensity resistance training amplifies muscle hypertrophy and functional gains in persons with parkinson's disease," Movement Disorders, vol. 21, no. 9, pp. 1444-1452, 2006.

[117] B. E. Fisher, A. D. Wu, G. J. Salem et al., "The effect of exercise training in improving motor performance and corticomotor excitability in people with early Parkinson's disease," Archives of Physical Medicine and Rehabilitation, vol. 89, no. 7, pp. 1221-1229, 2008.

[118] E. J. Protas, K. Mitchell, A. Williams, H. Qureshy, K. Caroline, and E. C. Lai, "Gait and step training to reduce falls in Parkinson's disease," NeuroRehabilitation, vol. 20, no. 3, pp. 183-190, 2005.

[119] M. Pohl, G. Rockstroh, S. Rückriem, G. Mrass, and J. Mehrholz, "Immediate effects of speed-dependent treadmill training on gait parameters in early Parkinson's disease," Archives of Physical Medicine and Rehabilitation, vol. 84, no. 12, pp. 1760-1766, 2003.

[120] M. E. Morris, R. Iansek, and B. Kirkwood, "A randomized controlled trial of movement strategies compared with exercise for people with Parkinson's disease," Movement Disorders, vol. 24, no. 1, pp. 64-71, 2009.

[121] M. E. Morris, C. L. Martin, and M. L. Schenkman, "Striding out with Parkinson disease: evidence-based physical therapy for gait disorders," Physical Therapy, vol. 90, no. 2, pp. 280$288,2010$.

[122] D. K. White, R. C. Wagenaar, T. D. Ellis, and L. TickleDegnen, "Changes in walking activity and endurance following rehabilitation for people with Parkinson disease," Archives of Physical Medicine and Rehabilitation, vol. 90, no. 1, pp. 4350, 2009.

[123] M. E. Morris, "Locomotor training in people with Parkinson disease," Physical Therapy, vol. 86, no. 10, pp. 1426-1435, 2006.

[124] K. Baker, L. Rochester, and A. Nieuwboer, "The immediate effect of attentional, auditory, and a combined cue strategy on gait during single and dual tasks in Parkinson's disease," Archives of Physical Medicine and Rehabilitation, vol. 88, no. 12, pp. 1593-1600, 2007.

[125] C. G. Canning, "The effect of directing attention during walking under dual-task conditions in Parkinson's disease," Parkinsonism and Related Disorders, vol. 11, no. 2, pp. 95-99, 2005.

[126] M. E. Morris, R. Iansek, T. A. Matyas, and J. J. Summers, "Stride length regulation in Parkinson's disease: normalization strategies and underlying mechanisms," Brain, vol. 119, part 2, pp. 551-568, 1996.

[127] L. Rochester, V. Hetherington, D. Jones et al., "The effect of external rhythmic cues (auditory and visual) on walking during a functional task in homes of people with Parkinson's disease," Archives of Physical Medicine and Rehabilitation, vol. 86, no. 5, pp. 999-1006, 2005.

[128] L. Rochester, K. Baker, V. Hetherington et al., "Evidence for motor learning in Parkinson's disease: acquisition, automaticity and retention of cued gait performance after training with external rhythmical cues," Brain Research, vol. 1319, pp. 103-111, 2010.

[129] B. Hu, N. de Bruin, J. B. Doan et al., "Walking with music is a safe and viable tool for gait training in parkinson's disease: 
the effect of a 13-week feasibility study on single and dual task walking," Parkinson's Disease, vol. 2010, Article ID 483530, 9 pages, 2010.

[130] L. Rochester, D. Rafferty, C. Dotchin, O. Msuya, V. Minde, and R. W. Walker, "The effect of cueing therapy on single and dual-task gait in a drug naïve population of people with parkinson's disease in Northern Tanzania," Movement Disorders, vol. 25, no. 7, pp. 906-911, 2010.

[131] L. Rochester, D. J. Burn, G. Woods, J. Godwin, and A. Nieuwboer, "Does auditory rhythmical cueing improve Gait in people with Parkinson's disease and cognitive impairment? A feasibility study," Movement Disorders, vol. 24, no. 6, pp. 839-845, 2009.

[132] A. L. Behrman, P. Teitelbaum, and J. H. Cauraugh, "Verbal instructional sets to normalise the temporal and spatial gait variables in Parkinson's disease," Journal of Neurology Neurosurgery and Psychiatry, vol. 65, no. 4, pp. 580-582, 1998.

[133] C. A. Lohnes and G. M. Earhart, "The impact of attentional, auditory, and combined cues on walking during single and cognitive dual tasks in Parkinson disease," Gait and Posture, vol. 33, no. 3, pp. 478-483, 2011.

[134] P. Fok, M. Farrell, and J. McMeeken, "Prioritizing gait in dual-task conditions in people with Parkinson's," Human Movement Science, vol. 29, no. 5, pp. 831-842, 2010.

[135] P. Fok, M. Farrell, and J. McMeeken, "The effect of dividing attention between walkingand auxiliary tasks in people with Parkinson's disease," Human Movement Science. In press.

[136] C. G. Canning, L. Ada, and E. Woodhouse, "Multiple-task walking training in people with mild to moderate Parkinson's disease: a pilot study," Clinical Rehabilitation, vol. 22, no. 3, pp. 226-233, 2008.

[137] S. G. Brauer and M. E. Morris, "Can people with Parkinson's disease improve dual tasking when walking?" Gait and Posture, vol. 31, no. 2, pp. 229-233, 2010.

[138] O. Beauchet, V. Dubost, G. Allali, R. Gonthier, F. R. Hermann, and R. W. Kressig, "'Faster counting while walking' as a predictor of falls in older adults," Age and Ageing, vol. 36, no. 4, pp. 418-423, 2007.

[139] O. Beauchet, G. Allali, C. Annweiler et al., "Does change in gait while counting backward predict the occurrence of a first fall in older adults?" Gerontology, vol. 54, no. 4, pp. 217-223, 2008.

[140] A. Bootsma-van der Wiel, J. Gussekloo, A. J. M. de Craen, E. van Exel, B. R. Bloem, and R. G. J. Westendorp, "Walking and talking as predictors of falls in the general population: the Leiden 85-plus study," Journal of the American Geriatrics Society, vol. 51, no. 10, pp. 1466-1471, 2003.

[141] L. Lundin-Olsson, L. Nyberg, and Y. Gustafson, "Stops walking when talking' as a predictor of falls in elderly people," Lancet, vol. 349, no. 9052, p. 617, 1997.

[142] K. L. McCulloch, V. Mercer, C. Giuliani, and S. Marshall, "Development of a clinical measure of dual-task performance in walking: reliability and preliminary validity of the walking and remembering test," Journal of Geriatric Physical Therapy, vol. 32, no. 1, pp. 2-9, 2009.

[143] A. Shumway-Cook, S. Brauer, and M. Woollacott, "Predicting the probability for falls in community-dwelling older adults using the Timed Up and Go Test," Physical Therapy, vol. 80, no. 9, pp. 896-903, 2000.

[144] J. Verghese, H. Buschke, L. Viola et al., "Validity of divided attention tasks in predicting falls in older individuals: a preliminary study," Journal of the American Geriatrics Society, vol. 50, no. 9, pp. 1572-1576, 2002.
[145] B. R. Bloem, Y. A. M. Grimbergen, M. Cramer, and V. V. Valkenburg, "'Stops walking when talking' does not predict falls in Parkinson's disease," Annals of Neurology, vol. 48, no. 2, p. 268, 2000.

[146] A. Mirelman, I. Maidan, T. Herman, J. E. Deutsch, N. Giladi, and J. M. Hausdorff, "Virtual reality for gait training: can it induce motor learning to enhance complex walking and reduce fall risk in patients with Parkinson's disease?" Journals of Gerontology, Series A, vol. 66, no. 2, pp. 234-240, 2011. 


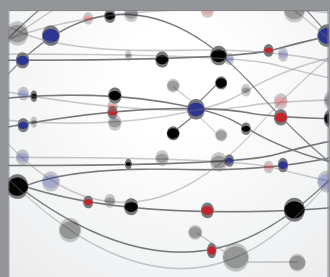

The Scientific World Journal
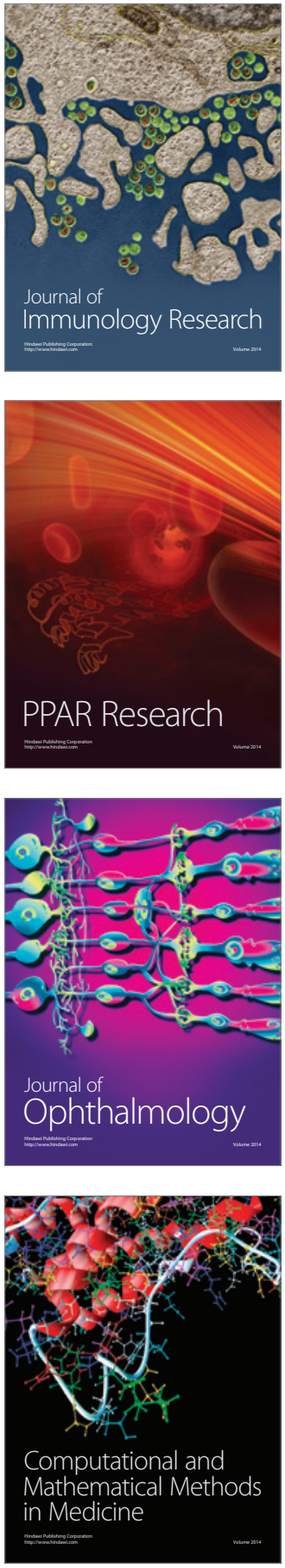

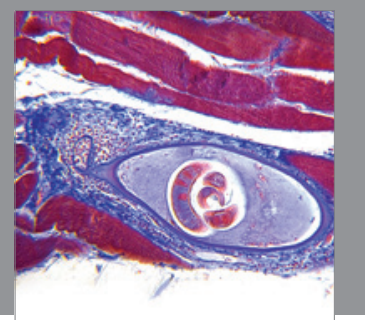

Gastroenterology

Research and Practice
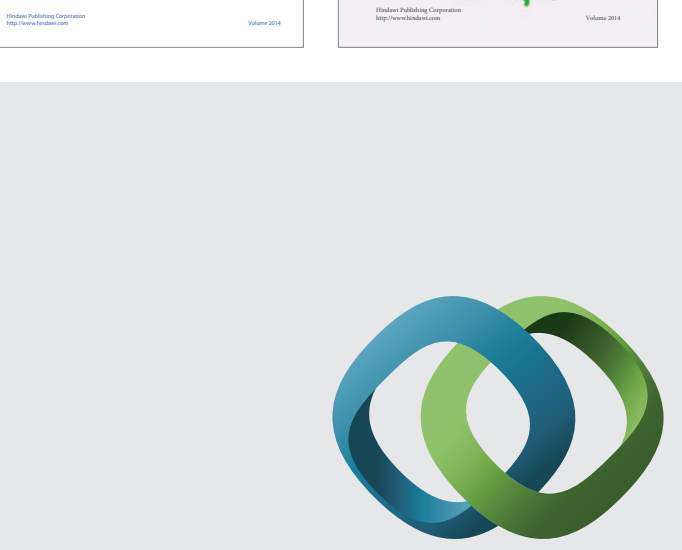

\section{Hindawi}

Submit your manuscripts at

http://www.hindawi.com
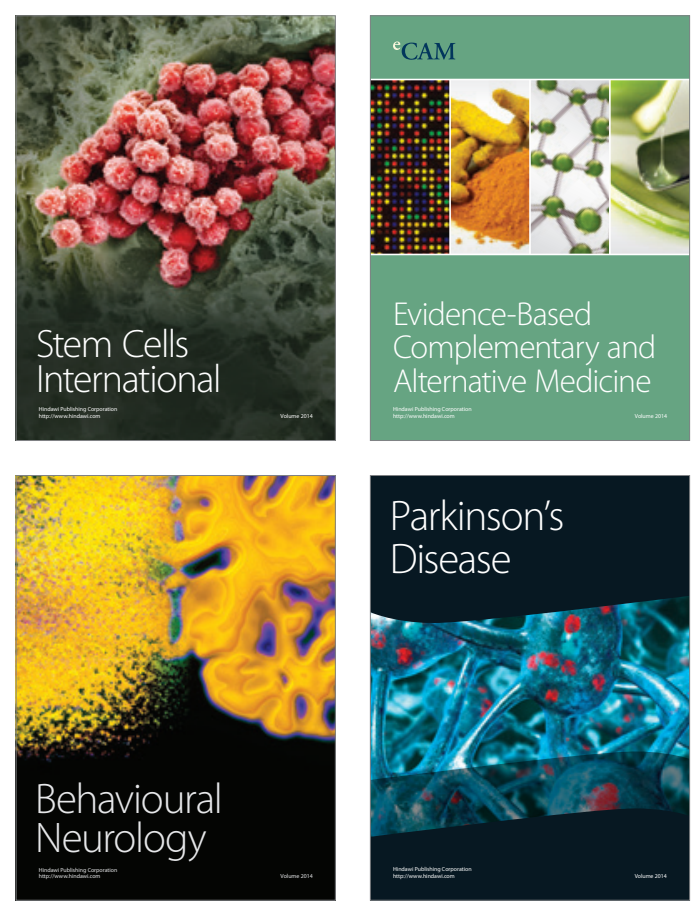

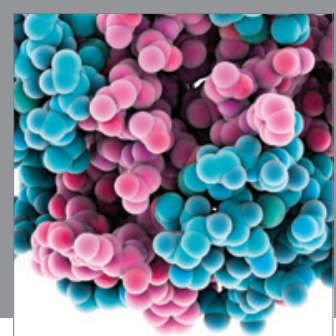

Journal of
Diabetes Research

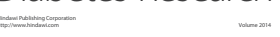

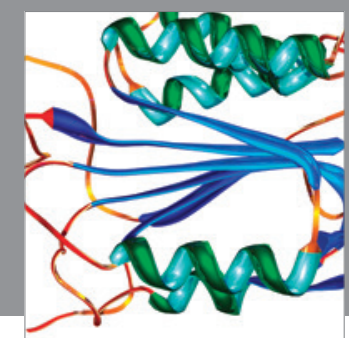

Disease Markers
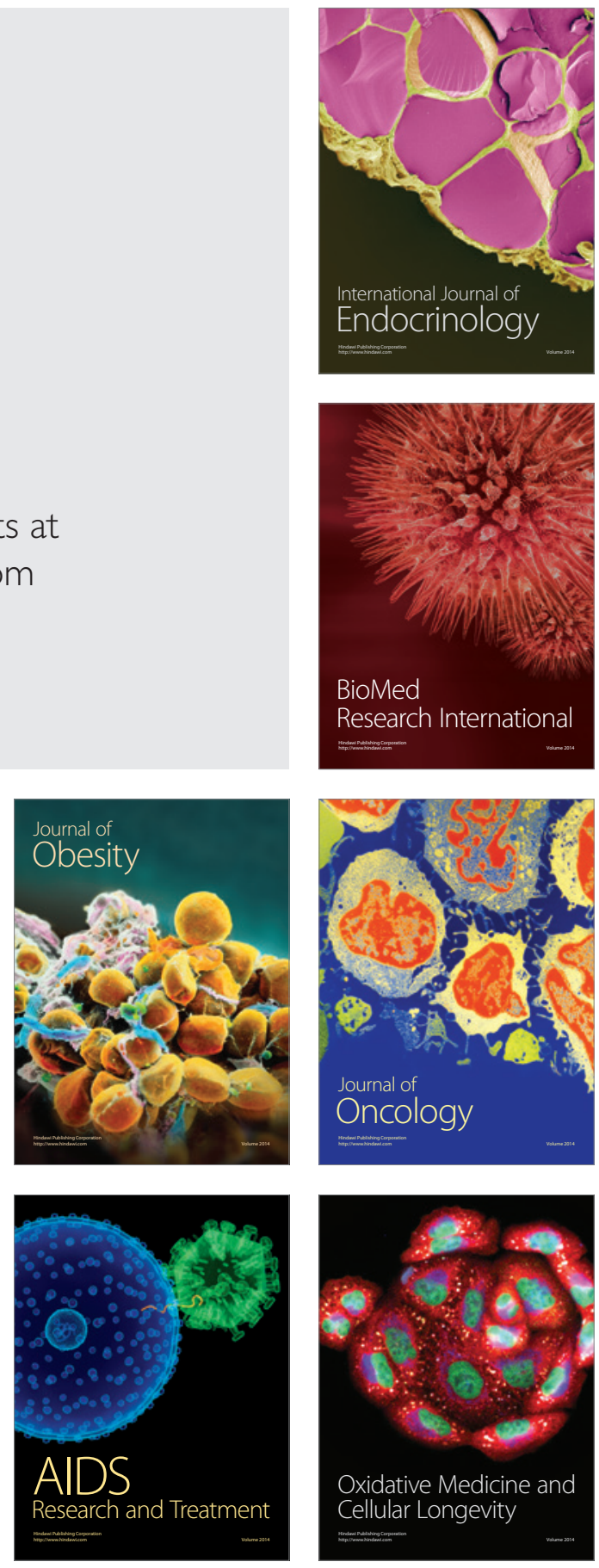